\title{
Biosynthesis of osmoregulated periplasmic glucans in Escherichia coli: the membrane-bound and the soluble periplasmic phosphoglycerol transferases are encoded by the same gene

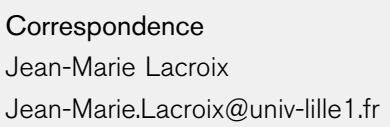 \\ Received 11 September 2007 \\ Revised 19 October 2007 \\ Accepted 25 October 2007

\author{
Yannick Lequette, Eric Lanfroy, Virginie Cogez, Jean-Pierre Bohin \\ and Jean-Marie Lacroix
}

\begin{abstract}
Unité de Glycobiologie Structurale et Fonctionnelle, UMR USTL/CNRS 8576 IFR147, Université des Sciences et Technologies de Lille, 59655 Villeneuve d'Ascq, Cedex, France
\end{abstract}

\begin{abstract}
In Escherichia coli, osmoregulated periplasmic glucans (OPGs) are highly substituted by phosphoglycerol, phosphoethanolamine and succinyl residues. A two-step model was proposed to account for phosphoglycerol substitution: first, the membrane-bound phosphoglycerol transferase I transfers residues from membrane phosphatidylglycerol to nascent OPG molecules; second, the periplasmic phosphoglycerol transferase II swaps residues from one OPG molecule to another. Gene $o p g B$ was reported to encode phosphoglycerol transferase I. In this study, we demonstrate that the periplasmic enzyme II is a soluble form of the membrane-bound enzyme I. In addition, timing of OPG substitution was investigated. OPG substitution by succinyl residues occurs rapidly, probably during the backbone polymerization, whereas phosphoglycerol addition is a very progressive process. Thus, both phosphoglycerol transferase activities appear biologically necessary for complete OPG substitution.
\end{abstract}

\section{INTRODUCTION}

Escherichia coli, like other Gram-negative bacteria, accumulates in its periplasmic space large amounts of short glucans (5-12 glucose units) in response to low osmolarity of the growth medium (Bohin \& Lacroix, 2006). In E. coli, osmoregulated periplasmic glucans (OPGs) consist of a linear backbone made of $\beta$-1,2-linked glucose units to which several $\beta$-1,6-linkage branches are added. This backbone is highly substituted by $s n$-1-phosphoglycerol, by phosphoethanolamine residues derived from membrane phospholipids, and by $\mathrm{O}$-succinyl ester of unknown origin (Kennedy, 1996). OPGs were described for the first time in E. coli by E. P. Kennedy and his coworkers during their study of phospholipid turnover (Van Golde et al., 1973), and they called them 'membrane-derived oligosaccharides' (MDOs) because of the membrane origin of the phosphoglycerol substituents.

Four genes are known to participate in OPG biosynthesis: two are needed for formation of the backbone (opgGH; Lacroix et al., 1991) and two are needed for its substitution by phosphoglycerol (opgB; Jackson et al., 1984; Lanfroy \& Bohin, 1993) and succinyl residues (opgC; Lacroix et al., 1999). Phosphatidylethanolamine, exogenously added to intact cells, was shown to be a source of phosphoethanolamine residues that are transferred to OPGs (Miller \&

Abbreviation: OPG, osmoregulated periplasmic glucan.
Kennedy, 1987), but this activity was not further characterized because attempts to develop an in vitro assay were unsuccessful, and its gene remained unidentified. Actually, only two enzyme activities have been accurately defined in vitro, both of them being involved in the phosphoglycerol substitution of OPGs.

The first described phosphoglycerol transferase was a soluble protein found in the periplasmic space (Goldberg et al., 1981). This enzyme was partially purified and has an apparent molecular mass of 56000 in gel permeation chromatography. In vitro, it catalyses the transfer of phosphoglycerol to unsubstituted OPG molecules or model $\beta$-glucosides in the presence of $\mathrm{Mn}^{2+}$. However, the enzyme is unable to use phosphatidylglycerol as the donor substrate, but it catalyses the interchange of phosphoglycerol residues between OPG molecules. Moreover, at low concentration of acceptor, the enzyme acts as a cyclase with the liberation of cyclic phosphoglycerol.

The second described activity was a membrane-bound phosphoglycerol transferase. In vitro, the enzyme catalyses the transfer of phosphoglycerol residues from phosphatidylglycerol to OPGs or to synthetic $\beta$-glucoside acceptors such as arbutin (Jackson \& Kennedy, 1983). In vivo, the transfer occurs also to arbutin, which is not transported or degraded by the bacterium. Thus, this enzyme should have its catalytic site present on the periplasmic side of the cytoplasmic membrane (Bohin \& Kennedy, 1984). 
Jackson \& Kennedy (1983) proposed a two-step model in which phosphoglycerol residues would be first transferred by the membrane-bound phosphoglycerol transferase I to newly synthesized glucans, still linked to the membrane. Then, the periplasmic phosphoglycerol transferase II would transfer those residues from one molecule of OPG (potentially still an acceptor in the first step) to another already liberated in the periplasmic space.

Mutants in the phosphoglycerol transfer (Jackson et al., 1984) were isolated on the basis of the toxic accumulation of diacylglycerol resulting from addition of arbutin to the growth medium of a diacylglycerol kinase mutant $(d g k)$. As expected from the model, the OPGs synthesized by these opgB mutants were devoid of phosphoglycerol. Moreover, crude extracts from an $o p g B$ strain still possessed the ability to remove phosphoglycerol residues from wild-type OPGs.

The $o p g B$ gene was cloned and localized immediately adjacent to the dnaTC operon (Lanfroy \& Bohin, 1993). Further characterization of the $\circ p g B$ gene product was hindered by an unusual instability of the protein, most of which was recovered in a soluble form. Thus, we decided to re-examine the relationship between the two enzymes.

\section{METHODS}

Bacterial strains and media. The E. coli K-12 strains and plasmids used in this study are listed in Table 1 . Bacteria were grown at $37{ }^{\circ} \mathrm{C}$ with vigorous shaking in Luria broth (LB) or in minimal medium 63 supplemented with the required metabolites and glucose as the carbon source (Miller, 1992). Solid media were obtained by adding agar $\left(15 \mathrm{~g} \mathrm{l}^{-1}\right)$. When low-osmolarity medium was required, lowosmolarity medium (LOS) or $\mathrm{LB}$ without $\mathrm{NaCl}$ was used (Lacroix et al., 1989). Antibiotics in media were used at the following concentrations: ampicillin, $50 \mu \mathrm{g} \mathrm{ml}^{-1}$; kanamycin, $50 \mu \mathrm{g} \mathrm{ml}^{-1}$; and tetracycline, $25 \mu \mathrm{g} \mathrm{ml}^{-1}$. X-Gal was used in media at the concentration of $20 \mu \mathrm{g} \mathrm{ml}^{-1}$.
Transduction and transformation. Transduction by phage P1vir was carried out according to Miller (1992). E. coli cells were made competent by the rubidium chloride technique (Miller, 1992).

Recombinant DNA techniques. Standard procedures (Sambrook et $a l ., 1989)$ were used for $\lambda$ DNA isolation, large-scale plasmid isolation and rapid analysis of recombinant plasmids. Restriction endonucleases (Biolabs), large (Klenow) fragment of DNA polymerase I, S1 nuclease and ligase of phage T4 (Gibco-BRL) were used according to the manufacturer's recommendations. Exonuclease III was used according to the method of Debarbieux et al. (1997).

DNA sequencing. Double-stranded opgB-blaM fusion plasmid DNAs were sequenced according to the Sequenase version 2.0 sequencing protocol (United States Biochemicals). The sequencing primer hybridizing at the $5^{\prime}$ end of blaM (5'-CCCACTCGTGCACCCAACT-3') was produced by Eurogentec.

Plasmid construction. The $\operatorname{opg} B$ gene was cloned as follows. $\lambda$ phage 8D1 DNA (Kohara et al., 1987) was first digested by SalI and KpnI (Fig. 1) and the $3.6 \mathrm{~kb}$ DNA fragment containing the $o p g B$ gene was cloned into pBGS18 digested by SalI and KpnI to give pNF601. Then, the $2.6 \mathrm{~kb}$ HindIII DNA fragment of pNF601 was cloned into the HindIII site of pYZ4 (Debarbieux et al., 1997) to give pNF604. For the construction of random fusion plasmids, the $3.2 \mathrm{~kb} S p h \mathrm{I}$ DNA fragment of pNF601 was cloned into the SphI site of pNF150 (Loubens et al., 1993), thus placing the $\operatorname{opgB}$ gene upstream of a truncated version of blaM (pNF673). The resulting plasmid, pNF673, was digested by SstI and SalI before digestion by exonuclease III, allowing deletions of the $\operatorname{opg} B$ gene only. Two additional $\operatorname{opg} B-b l a M$ fusions were generated as follows by direct cloning into restriction sites. For pNF710, plasmid pNF601 was digested by KpnI and DraI and the $1.2 \mathrm{~kb}$ DNA fragment was cloned into pNF150 digested by $K p n \mathrm{I}$ and $E c o$ RV. For pNF717, plasmid pNF601 was digested by EcoRI and BamHI, blunt-ended by the large fragment of DNA polymerase I, and the $2.7 \mathrm{~kb}$ DNA fragment was cloned into pNF150 digested by $X b a \mathrm{I}$ and blunt-ended by the large fragment of DNA polymerase I. For the expression of a truncated version of OpgB deleted of its two first transmembrane segments, pNF604 was digested by BamHI and blunt-ended by $\mathrm{S} 1$ nuclease, thus deleting a $340 \mathrm{bp}$ DNA fragment to give pNF721. Plasmid pNF596, in which $o p g B$ is fused to blaM after the codon for residue 164, was similarly engineered to give pNF723.

Table 1. Bacterial strains and plasmids

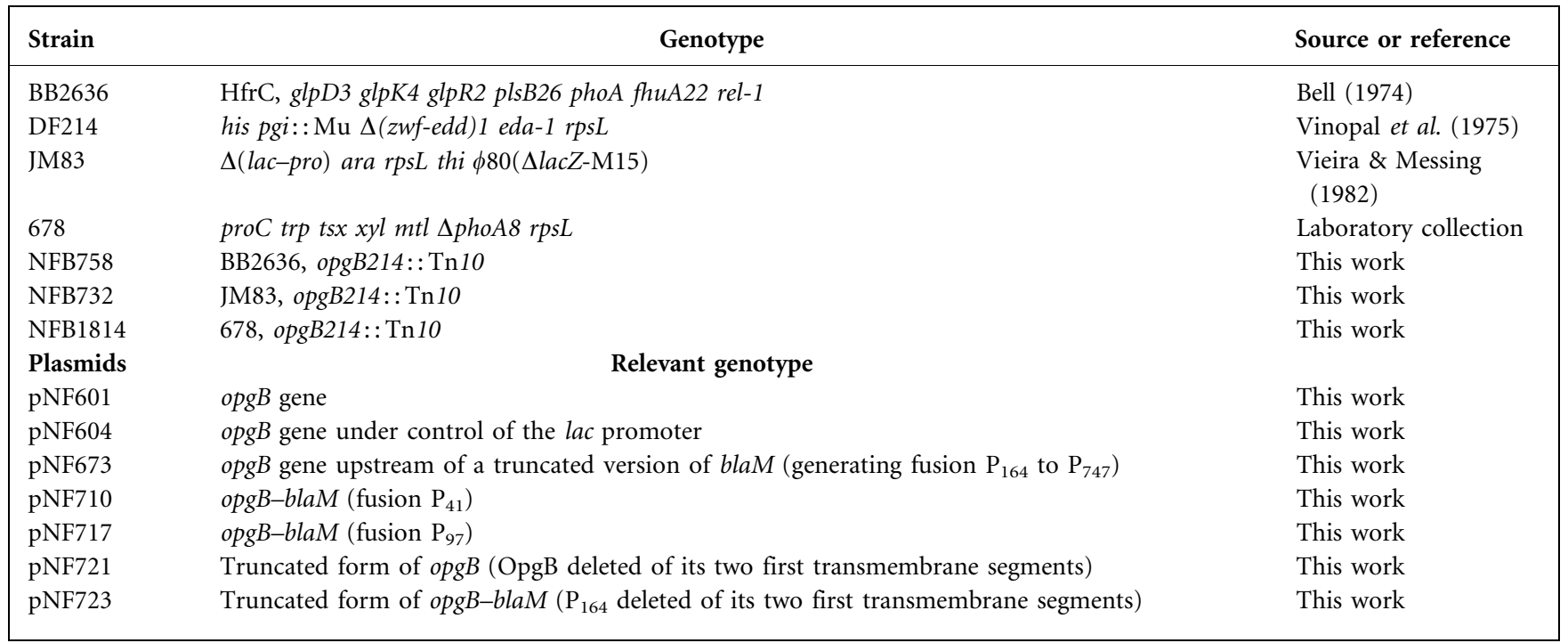



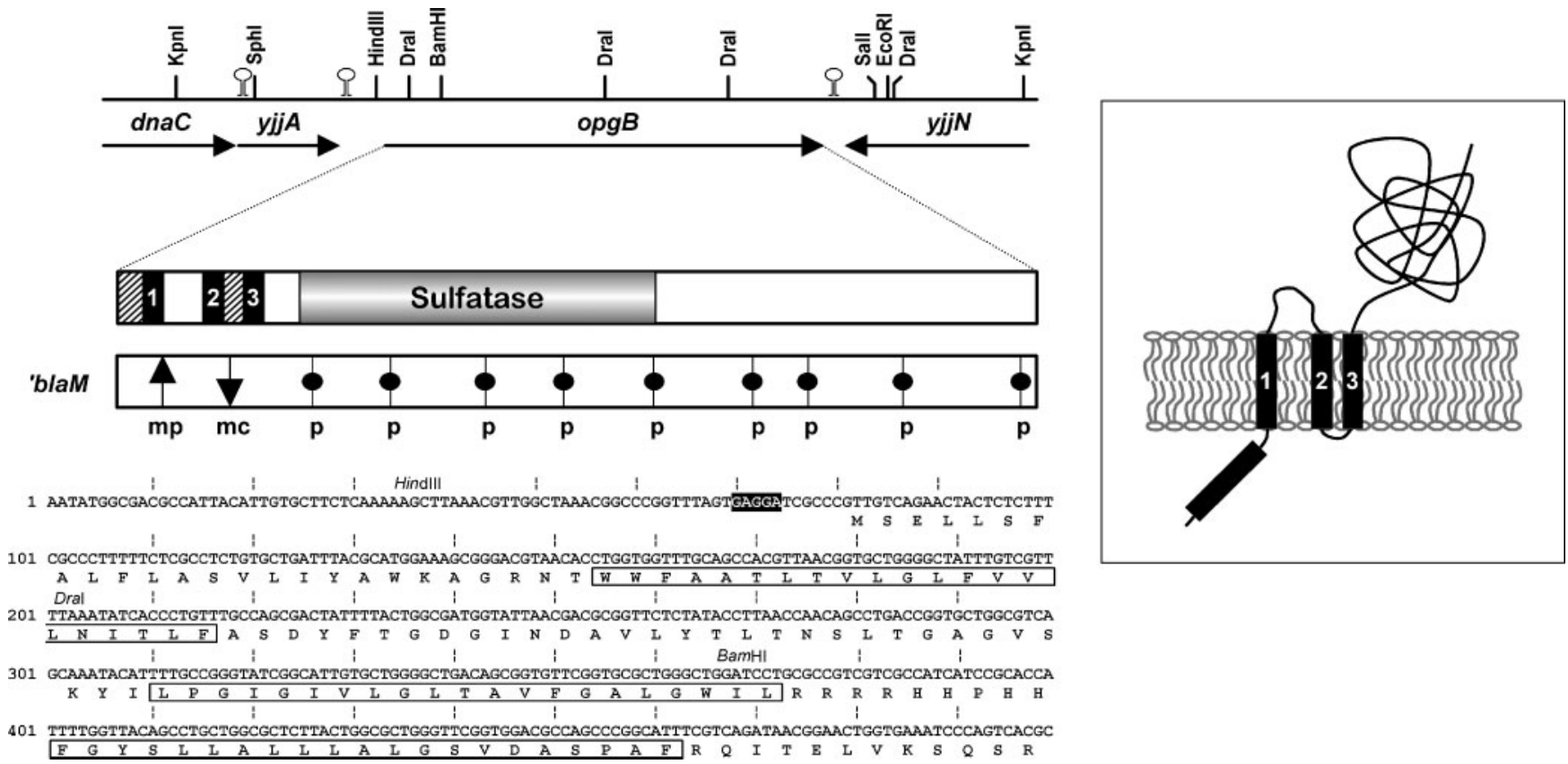

Fig. 1. Left top: genetic organization of the opgB region. Genes are indicated by black arrows. Relevant restriction sites are indicated and transcription terminators are shown as stem-loop structures. Middle: organization of the OpgB protein. The three transmembrane segments are coloured black and numbered. The cytoplasmic domains are hatched. The periplasmic domains are coloured white except for the sulfatase Pfam domain (Bateman et al., 2002), which is coloured grey. Each opgB-blaM gene fusion site is indicated. The location of the corresponding $\beta$-lactamase domain (Debarbieux et al., 1997) is abbreviated as follows: $\mathrm{mp}$, membrane-bound periplasmic; mc, membrane-bound cytoplasmic; $\mathrm{p}$, soluble periplasmic. Bottom: nucleotide and amino acid sequences of the beginning of $o p g B$. The potential ribosome-binding site is coloured black. The three putative transmembrane segments are boxed and relevant restriction sites are indicated. Right: model of the OpgB protein based upon the fusion results. The three transmembrane segments are numbered.

Preparation of $\left[2-{ }^{3} \mathbf{H}\right]$ glycerol-labelled OPGs. The glycerol auxotrophic strain BB2636 was grown in LOS medium $(5 \mathrm{ml})$ complemented with $0.45 \mathrm{mM}\left[2-{ }^{3} \mathrm{H}\right]$ glycerol $\left(1850 \mathrm{MBq} \mathrm{mmol}^{-1}\right)$. OPGs were extracted as described previously (Lacroix et al., 1989) and purified as follows. Pyridine extract was chromatographed on a Biogel P4 column (Bio-Rad). The column $(1.5 \mathrm{~cm} \times 65 \mathrm{~cm})$ was equilibrated with $0.5 \%$ acetic acid and eluted at a rate of $15 \mathrm{ml} \mathrm{h}^{-1}$ in the same buffer. Fractions (1.5 ml) containing OPGs were pooled, concentrated by rotary evaporation and desalted on a Biogel P2 column (Bio-Rad). Fractions containing OPGs were pooled and concentrated by rotary evaporation. These OPGs were used in the cyclic phosphoglycerol assay (see below) as a donor substrate of phosphoglycerol.

Assay of OPG substitution with $\left[\mathbf{2}^{3} \mathbf{H}\right]$ glycerol. The glycerol auxotrophic strain BB2636 and its $\operatorname{opgB}$ derivative (NFB758) were grown in LOS medium $(5 \mathrm{ml})$ complemented with $1.35 \mathrm{mM}$ $\left[2-{ }^{3} \mathrm{H}\right]$ glycerol $\left(296 \mathrm{MBq} \mathrm{mmol}^{-1}\right.$ ) and OPGs were extracted from overnight cultures as described previously (Lacroix et al., 1989).

Determination of neutral and anionic characteristics of OPGs. Cultures $(5 \mathrm{ml})$ of DF214 were grown in LOS medium; $0.24 \mathrm{mM} \mathrm{D}$ $\left[\mathrm{U}_{-}{ }^{14} \mathrm{C}\right]$ glucose $\left(125 \mathrm{MBq} \mathrm{mmol}^{-1}\right)$ was added in the exponential growth phase for various times and the reaction was stopped by adding $1 \mathrm{ml} 30 \%$ TCA. OPGs were then extracted and purified as described above and desalted on a PD10 column (Pharmacia Biotech) equilibrated with Tris/ $\mathrm{HCl} 10 \mathrm{mM}$ (pH 7.4). Fractions containing OPGs were pooled and chromatographed on a DEAE-Sephacel column $(1.5 \mathrm{~cm} \times 38 \mathrm{~cm}$, Pharmacia Biotech $)$ equilibrated with Tris/
$\mathrm{HCl} 10 \mathrm{mM}$ (pH 7.4) and eluted with the same buffer containing increasing concentrations of $\mathrm{NaCl}$ ranging from $0 \mathrm{M}$ to $1 \mathrm{M}$ by steps of $0.05 \mathrm{M}$. A volume of $60 \mathrm{ml}$ was used for each $\mathrm{NaCl}$ concentration and the volume of each collected fraction was $4 \mathrm{ml}$. When necessary, fractions of one peak were pooled and the succinyl substituents of OPGs were removed by incubation in $100 \mathrm{mM} \mathrm{KOH}$ for $2 \mathrm{~h}$ at $30{ }^{\circ} \mathrm{C}$. Treated OPGs were then desalted and chromatographed on a DEAESephacel column as previously described.

Determination of ampicillin resistance of cells expressing $\boldsymbol{\beta}$ lactamase fusion proteins. The ampicillin resistance of individual cells of NFB732 containing opgB-blaM fusion plasmids was determined according to Debarbieux et al. (1997).

Cellular location of fusion proteins. Soluble or membrane-bound location of fusion proteins was determined according to Loubens et al. (1993).

Partial purification of periplasmic proteins. Cells of strain 678 and derivatives were grown in $\mathrm{LB}$ without $\mathrm{NaCl}(100 \mathrm{ml})$. When cell densities reached $6 \times 10^{8}$ cells $\mathrm{ml}^{-1}$, periplasmic protein release was performed according to Loubens et al. (1993). One hundred microlitres of BSA ( $50 \mathrm{mg} \mathrm{ml}^{-1}$ ) was added to the periplasmic protein-containing supernatant as a tracer. This supernatant was chromatographed on Sephadex G-50 $(1 \mathrm{~cm} \times 18 \mathrm{~cm})$ at $4{ }^{\circ} \mathrm{C}$. Protein content of each fraction of $1 \mathrm{ml}$ was measured as $A_{260}$. Fractions containing proteins $(7 \mathrm{ml})$ were pooled, partially purified and concentrated in Macrosep 30K tubes (Pall Filtron) at $3000 \mathrm{~g}$ for $5 \mathrm{~h}$ at $4{ }^{\circ} \mathrm{C}$ to a final volume of $350 \mu \mathrm{l}$. 
Cyclic phosphoglycerol assay. The method was adapted from Goldberg et al. (1981), in which the activity of the enzyme was measured by cleavage and formation of cyclic phosphoglycerol from OPGs. The incubation buffer contained $50 \mathrm{mM}$ Tris/ $\mathrm{HCl}(\mathrm{pH} 7.8)$, $0.25 \mathrm{mM} \mathrm{MnCl}, 2.5 \mathrm{mg} \mathrm{BSA} \mathrm{ml}{ }^{-1}$ and $3.5 \mu \mathrm{M}\left[2-{ }^{3} \mathrm{H}\right]$ glycerollabelled OPGs (285 000 d.p.m. $\mathrm{nmol}^{-1}$ ). The final volume of reaction was $200 \mu \mathrm{l}$. After addition of periplasmic proteins $(145 \mu \mathrm{l})$, samples were incubated at $37{ }^{\circ} \mathrm{C}$ for various times. The reactions were stopped by the addition of $1 \mathrm{ml}$ charcoal suspension (Norit A, $20 \mathrm{mg} \mathrm{ml}^{-1}$ in distilled water). Samples were then vigorously agitated for $10 \mathrm{~min}$. Unlike OPGs, cyclic phosphoglycerol is not adsorbed on charcoal. Thus, the charcoal-containing labelled OPGs was removed by centrifugation at $8000 \mathrm{~g}$ for $10 \mathrm{~min}$. Radioactivity of the supernatant, containing $\left[2-{ }^{3} \mathrm{H}\right]$ glycerol-labelled cyclic phosphoglycerol liberated by the enzyme, was counted. Activity was calculated according to Goldberg et al. (1981).

\section{RESULTS AND DISCUSSION}

\section{Nucleotide sequence analysis of the opgB gene}

The open reading frame of the $\operatorname{opg} B$ gene encodes a 763 amino acid polypeptide beginning and ending at a TTG codon and a TAA codon respectively. Seven nucleotides upstream of the TTG codon is found a putative ribosomebinding site (Fig. 1). Eleven nucleotides downstream from the TAA is found a putative transcription terminator consisting of two inverted repeats of 12 nucleotides. Transcription analysis of the dnaTCyjjA operon, located upstream of the $o p g B$ gene, was reported (Masai \& Arai, 1988). The majority of the transcripts pass through a terminator downstream of $d n a C$ and terminate downstream of yjjA (Fig. 1). When introduced into strain NFB732 (opgB214::Tn10), plasmids pNF601 (SphI-SalI) and pNF604 (HindIII-SalI) (Fig. 1) complemented the phosphoglycerol transferase I defect (data not shown), indicating that the $2.6 \mathrm{~kb}$ insert of pNF604 contains the full-length $o p g B$ coding sequence. The HindIII site is located close to the ribosome-binding site, suggesting that in pNF604 the $\operatorname{opgB}$ promoter is missing and the open reading frame is transcribed from the lac promoter of the pYZ4 vector. For location of the promoter, two deletions of one opgB-blaM plasmid fusion (protein fusion point downstream of amino acid 164, see below) were performed. Strains harbouring plasmids with the XmnI deletion (removing the lac promoter of the plasmid vector) or plasmids with the SphI-HindIII deletion (see Fig. 1) remained ampicillin resistant. Strains harbouring plasmids with both deletions became ampicillin sensitive, indicating that the $o p g B$ promoter is located upstream of the HindIII site. Taken together, these data suggested that the $o p g B$ promoter is located between the $y j j A$ terminator and the HindIII site (Fig. 1).

\section{Amino acid sequence analysis of OpgB and prediction of its topology}

OpgB is a protein with a deduced molecular mass of $85494 \mathrm{Da}$. This is in agreement with the apparent molecular mass of $84000 \mathrm{Da}$ calculated from SDS-PAGE during the analysis of gene products located at the vicinity of the dnaTCyjjA operon (Masai \& Arai, 1988). The deduced protein $\mathrm{OpgB}$ was found to be a member of the alkaline phosphatase superfamily of metalloenzymes (Galperin et al., 1998) and its amino acids 163-448 form a conserved sulfatase domain (Pfam00884, http://pfam. jouy.inra.fr, Bateman et al., 2002). The dense alignment surface (DAS) method (http://www.sbc.su.se/ miklos/DAS, Cserzo et al., 1997) and the TopPred II algorithm (http:// bioweb.pasteur.fr/seqanal/interfaces/toppred.html, Claros \& von Heijne, 1994) allowed the prediction of the same three or four membrane-spanning segments in the first 124 amino acids (Fig. 1). We have no evidence for the existence of the putative transmembrane segment located in the vicinity of the $\mathrm{N}$-terminal part of OpgB, which is not represented in Fig. 1. Four consecutive arginine residues are found in a 9 amino acid sequence between the two last transmembrane segments. Taking into account the 'positive inside' rule, one can deduce that the hydrophilic C-terminal part of the protein (amino acids 125-763) is responsible for its catalytic activity on the periplasmic face of the membrane (Bohin \& Kennedy, 1984). To test the validity of this model (Fig. 1), $\beta$ lactamase was used as a topological reporter.

\section{Analysis of opgB-blaM gene fusions}

Twenty-three in-frame $o p g B$-blaM fusions were obtained after exonuclease III digestion (see Methods). The position of the $\beta$-lactamase moiety (cytoplasmic or periplasmic) was determined for each fusion by streaking the colonies, up to individual cells, on LB agar plates containing $50 \mu \mathrm{g}$ ampicillin $\mathrm{ml}^{-1}$. All the fusions conferred resistance on individual cells, indicating that these strains have a $\beta$ lactamase moiety in the periplasmic space. The fusion point between the $o p g B$ and truncated blaM genes of the 23 fusions was determined by DNA sequencing. Then, nine of them, regularly spaced over the OpgB protein, were further characterized. Protein fusion points were downstream of amino acids $164\left(\mathrm{P}_{164}\right), 228\left(\mathrm{P}_{228}\right), 307\left(\mathrm{P}_{307}\right), 371\left(\mathrm{P}_{371}\right), 446$ $\left(\mathrm{P}_{446}\right), 529\left(\mathrm{P}_{529}\right), 574\left(\mathrm{P}_{574}\right), 652\left(\mathrm{P}_{652}\right)$ and $747\left(\mathrm{P}_{747}\right)$ (i.e. after transmembrane segment 3 , see Fig. 1). This random procedure did not give a fusion in the first 163 amino acids. Two opgB-blaM fusions were then generated by direct cloning into restriction sites (see Methods) with fusion points downstream of amino acids $41\left(\mathrm{P}_{41}\right)$ and $97\left(\mathrm{P}_{97}\right)$ (i.e. at the end of the predicted transmembrane segments 1 and 2 respectively, see Fig. 1). Ampicillin resistance conferred by these two fusions indicated that the $\beta$-lactamase moieties were periplasmic and cytoplasmic respectively (Fig. 1). To confirm the location of each fusion protein, crude extracts were prepared from cells of strain NFB732 harbouring the corresponding plasmids and the $\beta$-lactamase activity was determined in the supernatant (soluble activity) and the pellet (insoluble membrane-bound activity) after centrifugation at $150000 \mathrm{~g}$ for $2 \mathrm{~h}$ as described previously (Loubens et al., 1993). As expected, most of the $\beta$-lactamase activity was recovered in the pellet for the two first fusion proteins 
( $89 \%$ and $83 \%$ for $\mathrm{P}_{41}$ and $\mathrm{P}_{97}$ respectively). Surprisingly, most of the $\beta$-lactamase activity was recovered in the supernatant for the nine other fusion proteins (99\%, $78 \%$, $73 \%, 78 \%, 84 \%, 84 \%, 76 \%, 69 \%$ and $87 \%$ for $\mathrm{P}_{164}, \mathrm{P}_{228}$, $\mathrm{P}_{307}, \mathrm{P}_{371}, \mathrm{P}_{446}, \mathrm{P}_{529}, \mathrm{P}_{574}, \mathrm{P}_{652}$ and $\mathrm{P}_{747}$ respectively). Thus, only $\mathrm{P}_{41}$ and $\mathrm{P}_{97}$ were found to be membrane-bound. These results confirmed the topological orientation of the three membrane-spanning segments. All the fusions beyond amino acid 163 were found to be essentially soluble. These results suggested a proteolytic cleavage of OpgB.

\section{Phosphoglycerol transferase II is encoded by opgB}

Phosphoglycerol transferase II was initially characterized from soluble proteins extracted from $600 \mathrm{~g}$ (wet weight) of E. coli cells after several purification steps (Goldberg et al., 1981). When $\operatorname{opg} B$ mutants were obtained, their phosphoglycerol transferase II activities were determined by the phosphoglycerol cyclase test on total soluble proteins in crude extracts without subsequent purification steps. The activity was found to be similar in the mutant strains and in the wild-type strain $\left(0.33\right.$ and $0.31 \mathrm{U} \mathrm{mg}^{-1} \mathrm{~h}^{-1}$ respectively), suggesting that two different genes encode the two phosphoglycerol transferases (Jackson et al., 1984). In this work, we developed a micro-method using partially purified periplasmic extracts (see Methods). Three strains were compared for their phosphoglycerol cyclase activities (see Methods): strain 678, from which periplasmic extracts are particularly easy to obtain (Loubens et al., 1993), an $o p g B$ derivative of strain 678 (NFB1814) and strain 678 harbouring plasmid pNF604 $\left(o p g B^{+}\right)$. Accumulation of tritiated cyclic phosphoglycerol increased linearly for at least $2 \mathrm{~h}$ in assays performed with extracts from strain 678 and strain 678 (pNF604). The level of cyclase activity was $0.25 \pm 0.01 \mathrm{U}(\mathrm{mg} \text { protein })^{-1} \mathrm{~h}^{-1}, 5.37 \pm 0.50 \mathrm{U}$ (mg protein $)^{-1} \mathrm{~h}^{-1}$ and $0.02 \pm 0.01 \mathrm{U}(\mathrm{mg} \text { protein })^{-1} \mathrm{~h}^{-1}$ in periplasmic extracts from strain 678, strain 678(pNF604) and strain NFB1814 respectively. Whereas only a residual activity could be detected in NFB1814, a 25-fold increase in cyclase activity resulted from the introduction of the $o p g B^{+}$plasmid in strain 678. Because of the difference between our data and those published by Jackson et al. (1984), crude extracts were also tested on our strains. Tritiated glycerol liberation activities were $0.70 \pm 0.01 \mathrm{U}(\mathrm{mg} \text { protein })^{-1} \mathrm{~h}^{-1}$ and $0.30 \pm 0.01 \mathrm{U}(\mathrm{mg}$ protein $)^{-1} \mathrm{~h}^{-1}$ for strain 678 and NFB1814 respectively. The apparent discrepancy between the data is most probably the result of a non-specific cytoplasmic activity present in crude extracts but absent from periplasmic extracts. Thus, the membrane-bound and the soluble phosphoglycerol transferase are encoded by the same gene.

\section{Analysis of phosphoglycerol transferase II activity in vivo}

From the model (Fig. 1) it is obvious that the cleavage should occur before the conserved sulfatase domain, just downstream of the third transmembrane segment. A deletion of plasmid pNF604 allowed the fusion of the two first codons of lacZ (encoded by the vector) with the codon corresponding to the last residue of the second transmembrane segment of OpgB (pNF721). The SignalP program (Nielsen et al., 1997, http://www.cbs.dtu.dk/ services/SignalP/) allowed the prediction that signal peptidase I could recognize the remaining transmembrane segment as a signal sequence with a cleavage site between $\mathrm{Ala}_{124}$ and $\mathrm{Ser}_{125}$. A similar construction was done with $\mathrm{OpgB}$ fused to BlaM downstream of amino acid 164, and its ampicillin-resistance phenotype indicated that the hybrid protein was expressed as a soluble periplasmic protein.

Plasmid pNF721 was introduced into strain BB2636 (a glycerol auxotroph that enables a specific and quantitative labelling of OPGs with $\left[2-{ }^{3} \mathrm{H}\right]$ glycerol, Bohin \& Kennedy, 1984) and into its $o p g B$ derivative NFB758. OPGs were extracted from overnight cultures. In the presence of the plasmid, the OPG radioactivity remained null in the $o p g B$ background but was increased by $79 \%$ in the wild-type background. These OPGs were further analysed by DEAESephacel chromatography (Fig. 2). As described previously, OPGs of E. coli can be separated by this method in five subfractions corresponding to increasing charge-to-mass ratios (Lacroix et al., 1999, see Fig. 3). In strain BB2636(pNF721), the glycerol content of subfractions IV

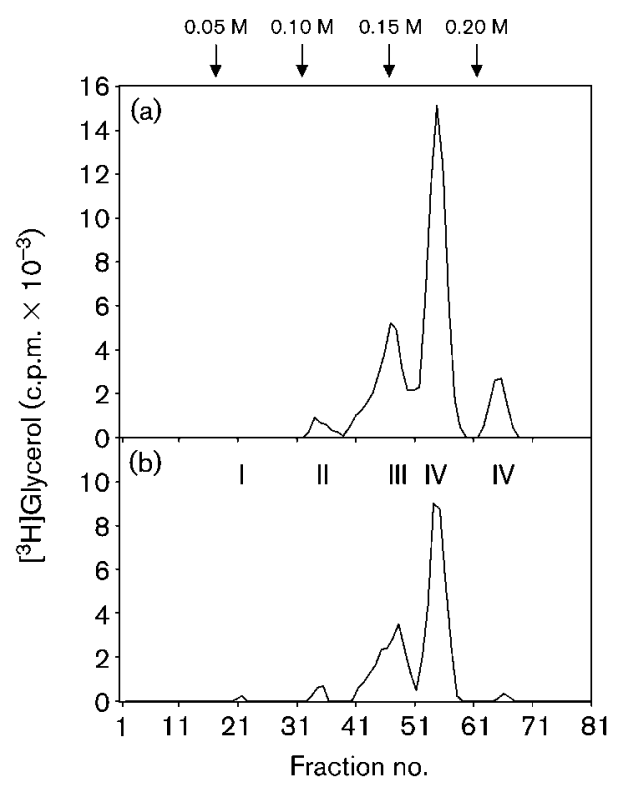

Fig. 2. DEAE-Sephacel anion-exchange column chromatography profiles of $\left[2-{ }^{3} \mathrm{H}\right]$ glycerol-labelled OPGs from strains BB2636 $\left(\right.$ opg $\left.B^{+}\right)$harbouring plasmid pNF721 (a) or not (b). pNF721 allowed the expression of a truncated OpgB protein deleted of its first two transmembrane segments. lonic strength was increased by steps of $0.05 \mathrm{M} \mathrm{NaCl}$ at fractions indicated by the arrows. Fractions $(4 \mathrm{ml})$ were collected and radioactivity was measured in aliquots. 


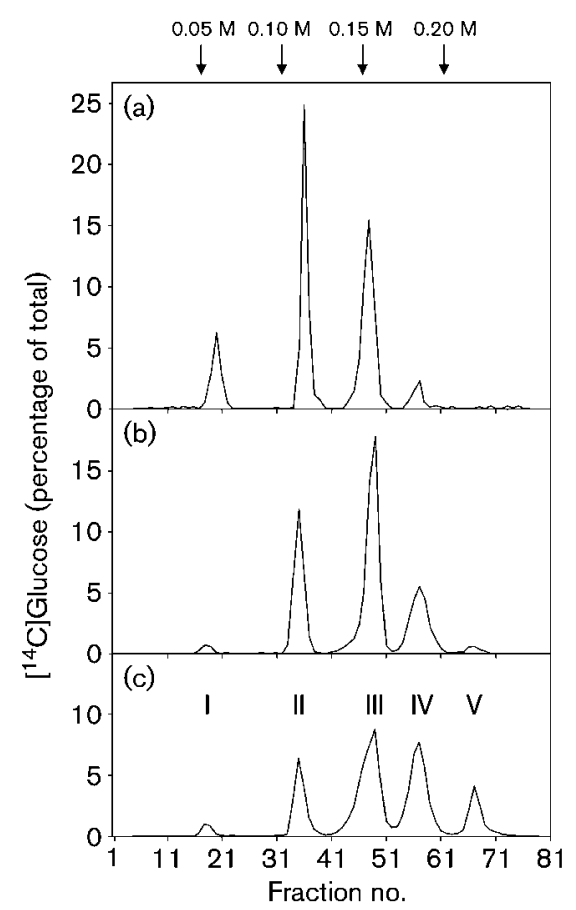

Fig. 3. DEAE-Sephacel anion-exchange column chromatography profiles of $\left[\mathrm{U}-{ }^{14} \mathrm{C}\right]$ glucose-labelled OPGs from strain DF214. Labelling was done for $10 \mathrm{~min}(\mathrm{a}), 3 \mathrm{~h}$ (b), or $6 \mathrm{~h}$ (c). lonic strength was increased by steps of $0.05 \mathrm{M} \mathrm{NaCl}$ at fractions indicated by the arrows. Fractions $(4 \mathrm{ml})$ were collected and radioactivity was measured in aliquots. Peaks: I, neutral glucans; II-V, anionic glucans.

and V was strongly increased (Fig. 2). In conclusion, when the two first transmembrane segments of OpgB are deleted, a periplasmic protein is expressed that cannot complement a defect of phosphoglycerol transferase I activity but can increase significantly the phosphoglycerol substitution of OPGs in a wild-type background. These results demonstrate allotopic properties (Racker, 1967) of OpgB, which can use phosphatidylglycerol as a donor substrate only when anchored in the cell membrane, in complete agreement with the two-step mechanism proposed by Jackson \& Kennedy (1983).

\section{Time-course of the phosphoglycerol substitution of OPGs}

In the two-step model, OPGs still linked to or in the close vicinity of the membrane are substrates for the membranebound enzyme whereas OPGs liberated after a delay in the periplasmic space are substrates for the soluble enzyme. In order to test this model, $\left[{ }^{14} \mathrm{C}\right]$ glucose incorporation was followed in OPGs of strain DF214. This strain is defective for both phosphoglucose isomerase and glucose-6-phosphate dehydrogenase activities and can synthesize UDPglucose, and consequently OPGs, only when exogenous glucose is provided in the medium, thus allowing specific labelling of OPGs. DF214 was grown in low-osmolarity medium without glucose added until mid-exponential phase. D-[U- $\left.{ }^{14} \mathrm{C}\right]$ Glucose was then added to the medium and aliquots of the culture were taken up after $10 \mathrm{~min}, 3 \mathrm{~h}$ (exponential growth phase) and $6 \mathrm{~h}$ (stationary growth phase). OPGs were extracted and analysed by DEAESephacel chromatography (see Methods). The elution profiles for the three kinds of OPG preparations were markedly different. Actually, the time-course of phosphoglycerol substitution was followed from extracts containing only newly synthesized OPGs (10 min), from extracts containing a mixture of new and mature OPG molecules $(3 \mathrm{~h})$ and from extracts containing only mature OPG molecules $(6 \mathrm{~h})$ since OPGs are no longer synthesized during stationary growth phase (J.-P. Bohin \& J.-M. Lacroix, unpublished results). As previously observed (Lacroix et al., 1999), OPGs extracted from cells in stationary phase had various mass-to-charge ratios and were separated into five subfractions, representing $2 \%(\mathrm{I})$, $16 \%$ (II), $38 \%$ (III), $30 \%$ (IV) and $14 \%$ (V) of the total, respectively (Fig. 3c). OPGs extracted after $10 \mathrm{~min}$ of synthesis were much less anionic. Subfraction $\mathrm{V}$ was absent and subfractions I-IV represented $14 \%$ (I), $40 \%$ (II), $41 \%$ (III) and 5\% (IV) of the total (Fig. 3a). OPGs extracted after $3 \mathrm{~h}$ showed an intermediate distribution (Fig. 3b). Newly synthesized OPGs (10 min) were further analysed. Subfractions II and III were submitted to an alkaline hydrolysis to remove succinyl residues linked to the backbone by ester linkages, then analysed once again by DEAE-Sephacel chromatography (amounts in subfraction IV were too low to allow accurate analysis). Sixty per cent of the treated subfraction II was now eluted in the neutral subfraction I while $40 \%$ remained eluted in subfraction II; $60 \%$ of the treated subfraction III was eluted in the neutral subfraction I and $40 \%$ in subfraction II (data not shown). Thus, $14 \%$ of the newly synthesized OPGs were neutral, $65 \%$ were substituted by succinyl residues, and $33 \%$ were substituted by phosphoglycerol residues $(17 \%$ being substituted by both substituents). Eighty per cent of the OPGs extracted from $o p g B$ cells in stationary phase are substituted by succinyl residues (Lacroix et al., 1999) and this level is probably lower in wild-type cells, where OpgB and $\mathrm{OpgC}$ are in competition for the same acceptor substrate. Thus, one can consider that succinyl substitution was already achieved in $10 \mathrm{~min}$ while phosphoglycerol substitution was a much slower process.

\section{Concluding remarks}

The $\operatorname{opg} B$ gene encodes a protein which is anchored in the cytoplasmic membrane and has the properties of phosphoglycerol transferase I. After post-translational modification (probable cleavage between $\mathrm{Ala}_{124}$ and $\mathrm{Ser}_{125}$ ), this protein becomes a soluble, periplasmic protein whose enzymic activity changes into phosphoglycerol transferase II. The $\operatorname{cgmB}$ gene, encoding a phosphoglycerol transferase catalysing phosphoglycerol substitution of OPGs in Sinorhizobium meliloti, was characterized by Wang et al. 
(1999). Because CgmB of S. meliloti and OpgB of E. coli showed no significant similarity, and because CgmB is a soluble periplasmic protein, the authors suggested that CgmB may be more similar to phosphoglycerol transferase II. But, since in E. coli both phosphoglycerol transferase activities are encoded by the same gene, it appears that this hypothesis was not correct. In addition, no significant similarity was observed between Cgm and OpgC, two enzymes catalysing the succinyl substitution of OPGs in Brucella abortus (Roset et al., 2006) and in E. coli (Lacroix et al., 1999) respectively, or between these enzymes and both kinds of phosphoglycerol transferases. Thus, the various OPG substitution enzymes, which catalyse very similar reactions, have probably emerged from independent evolutions.

In E. coli, OPG synthesis occurs essentially at the innermembrane level in a complex of proteins including four membrane proteins, two periplasmic proteins and one cytoplasmic protein (Bohin \& Lacroix, 2006). Succinyl substitution occurs very early in the synthetic process and probably during the glucose backbone synthesis itself. A primary substitution by phosphoglycerol residues occurs at the same time. However, supplementary substitution, facilitated by a soluble periplasmic enzyme, is needed to achieve complete anionic substitution of OPGs.

\section{ACKNOWLEDGEMENTS}

Y.L. received a doctoral studentship from the Ministère de l'Enseignement Supérieur, de la Recherche et de la Technologie and from the Fondation pour la Recherche Médicale. This research was supported by a grant from the Centre National de la Recherche Scientifique (UMR8576).

\section{REFERENCES}

Bateman, A., Birney, E., Cerruti, L., Durbin, R., Etwiller, L., Eddy, S. R., Griffiths-Jones, S., Howe, K. L., Marshall, M. \& Sonnhammer, E. L. L. (2002). The Pfam protein families database. Nucleic Acids Res 30, 276-280.

Bell, R. M. (1974). Mutants of Escherichia coli defective in membrane phospholipid synthesis: macromolecular synthesis in an sn-glycerol-3phosphate acyltransferase Km mutant. J Bacteriol 117, 1065-1076.

Bohin, J.-P. \& Kennedy, E. P. (1984). Regulation of the synthesis of membrane-derived oligosaccharides in Escherichia coli. Assay of phosphoglycerol transferase I in vivo. J Biol Chem 259, 8388-8393.

Bohin, J.-P. \& Lacroix, J.-M. (2006). Osmoregulation in the periplasm. In The Periplasm, pp. 325-341. Edited by M. Ehrmann. Washington, DC: American Society for Microbiology.

Claros, M. G. \& von Heijne, G. (1994). TopPred II: an improved software for membrane protein structure predictions. Comput Appl Biosci 10, 685-686.

Cserzo, M., Wallin, E., Simon, I., von Heijne, G. \& Elofsson, A. (1997). Prediction of transmembrane alpha-helices in prokaryotic membrane protein: the dense alignment surface method. Protein Eng 10, 673-676.

Debarbieux, L., Bohin, A. \& Bohin, J.-P. (1997). Topological analysis of the membrane-bound glucosyltransferase, $\mathrm{MdoH}$, required for osmoregulated periplasmic glucan synthesis in Escherichia coli. J Bacteriol 179, 6692-6698.

Galperin, M. Y., Bairoch, A. \& Koonin, E. V. (1998). A superfamily of metalloenzymes unifies phosphopentomutase and cofactor-independent phosphoglycerate mutase with alkaline phosphatases and sulfatases. Protein Sci 7, 1829-1835.

Goldberg, D. E., Rumley, M. K. \& Kennedy, E. P. (1981). The biosynthesis of membrane-derived oligosaccharides: a periplasmic phosphoglycerol transferase. Proc Natl Acad Sci U S A 78, 5513-5517.

Jackson, B. J. \& Kennedy, E. P. (1983). The biosynthesis of membrane-derived oligosaccharides: a membrane-bound phosphoglycerol transferase. J Biol Chem 258, 2394-2398.

Jackson, B. J., Bohin, J.-P. \& Kennedy, E. P. (1984). Biosynthesis of membrane derived oligosaccharides: characterization of $o p g B$ mutants defective in phosphoglycerol transferase I activity. J Bacteriol 160, 976-981.

Kennedy, E. P. (1996). Membrane derived oligosaccharides (periplasmic beta-D-glucans) of Escherichia coli. In Escherichia coli and Salmonella: Cellular and Molecular Biology, 2nd edn, pp. 1064-1074. Edited by F. C. Neidhardt and others. Washington, DC: American Society for Microbiology.

Kohara, Y., Akiyama, K. \& Isono, K. (1987). The physical map of the whole Escherichia coli chromosome: application of a new strategy for rapid analysis and sorting of a large genomic library. Cell 50, 495-508.

Lacroix, J.-M., Tempête, M., Menichi, B. \& Bohin, J.-P. (1989). Molecular cloning and expression of a locus $(m d o A)$ implicated in the biosynthesis of the membrane-derived oligosaccharides in Escherichia coli. Mol Microbiol 3, 1173-1182.

Lacroix, J.-M., Loubens, I., Tempête, M., Menichi, B. \& Bohin, J.-P. (1991). The $m d o A$ locus of Escherichia coli consists of an operon under osmotic control. Mol Microbiol 5, 1745-1753.

Lacroix, J.-M., Lanfroy, E., Cogez, V., Lequette, Y., Bohin, A. \& Bohin, J.-P. (1999). The mdoC gene of Escherichia coli encodes a membrane protein that is required for succinylation of osmoregulated periplasmic glucans. J Bacteriol 181, 3626-3631.

Lanfroy, E. \& Bohin, J.-P. (1993). Physical map location of the Escherichia coli gene encoding phosphoglycerol transferase I. J Bacteriol 175, 5736-5737.

Loubens, I., Debarbieux, L., Bohin, A., Lacroix, J.-M. \& Bohin, J.-P. (1993). Homology between a genetic locus $(m d o A)$ involved in the osmoregulated biosynthesis of periplasmic glucans in Escherichia coli and a genetic locus ( $h r p M)$ controlling pathogenicity of Pseudomonas syringae. Mol Microbiol 10, 329-340.

Masai, H. \& Arai, K.-I. (1988). Operon structure of dnaT and $d n a C$ genes essential for normal and stable DNA replication of Escherichia coli chromosome. J Biol Chem 263, 15083-15093.

Miller, J. H. (1992). A Short Course in Bacterial Genetics. A Laboratory Manual and Handbook for Escherichia coli and Related Bacteria. Cold Spring Harbor, NY: Cold Spring Harbor Laboratory.

Miller, K. J. \& Kennedy, E. P. (1987). Transfer of phosphoethanolamine residues from phosphatidylethanolamine to the membranederived oligosaccharides of Escherichia coli. J Bacteriol 169, 682-686.

Nielsen, H., Engelbrecht, J., Brunak, S. \& von Heijne, G. (1997). Identification of prokaryotic and eukaryotic signal peptides and prediction of their cleavage sites. Protein Eng 10, 1-6.

Racker, E. (1967). Resolution and reconstitution of the inner mitochondrial membrane. Fed Proc 26, 1335-1340.

Roset, M. S., Ciocchini, A. E., Ugalde, R. A. \& Inon de lannino, N. (2006). The Brucella abortus cyclic beta-1,2-glucan virulence factor is substituted with $O$-ester-linked succinyl residues. J Bacteriol 188, 5003-5013. 
Sambrook, J., Fritsch, E. F. \& Maniatis, T. (1989). Molecular Cloning: a Laboratory Manual. Cold Spring Harbor, NY: Cold Spring Harbor Laboratory.

Van Golde, L. M. G., Schulman, H. \& Kennedy, E. P. (1973). Metabolism of membrane phospholipids and its relation to a novel class of oligosaccharides in Escherichia coli. Proc Natl Acad Sci U S A 70, 1368-1372.

Vieira, J. \& Messing, J. (1982). The pUC plasmids, an M13 mp7derived system for insertion mutagenesis and sequencing with synthetic universal primers. Gene 19, 259-268.
Vinopal, R. T., Hillman, J. D., Schulman, H., Reznikoff, W. S. \& Fraenkel, D. G. (1975). New phosphoglucose isomerase mutants of Escherichia coli. J Bacteriol 122, 1172-1174.

Wang, P., Ingram-Smith, C., Hadley, J. A. \& Miller, K. J. (1999).

Cloning, sequencing, and characterization of the $\operatorname{cgmB}$ gene of Sinorhizobium meliloti involved in cyclic beta-glucan biosynthesis. J Bacteriol 181, 4576-4583.

Edited by: J. Green 